\title{
Data Analysis Based on E-Commerce Platform
}

\author{
Junli Wang ${ }^{1}$, Yuting Zhang ${ }^{1}$, Lu Cao ${ }^{1}$ \\ ${ }^{1}$ Hainan University, Haikou, Hainan, 570228
}

\section{KEYWORDS: E-Commerce, Platform, Data Analysis}

\begin{abstract}
Data in everyday life everywhere, and people's lives. With the development of information society, the needs of various industries for analysis of data are also growing. However, the current domestic data analysis industry started late, small-scale, without a complete system and improve service delivery model, and even the national statistical offices do not have a complete database management system, a large number of data resources to be abandoned. Meanwhile, with the development of information society, e-commerce has become the future direction of business development, but at this stage, there are many gaps and development of e-commerce transactions invisible, thereby constructing data analysis, e-commerce platform idea came into being.
\end{abstract}

\section{Introduction}

Data analysis services is a very special form of service, currently in China has not yet formed a complete service model, there is no pattern to form a market-oriented service, in people's vision has not been a high degree of recognition. It is worth mentioning that in the data analysis stock market analysis software and stock analysts channel for a large number of investors still have considerable appeal, because these data so that investors play heart. In fact, the data analysis in people's lives, there is the ever-present, ever-present, a large number of public data analysis has with people's lives, these basic services are free, but also a welfare society in to promote its development. With the development of information society, the class fee data is rapidly developing due to data collection, processing, aggregation, storage, management, analysis and mining is a "high cost", "high-tech" and "high input" service format, so in addition to our country tune, pollsters difficult to support this market.

China's current e-commerce entity transactions have been very strong and they the most active and most areas of the market selling point, and is the main battleground of e-commerce, intense competition can be imagined. Invisible transactions to Google and Baidu, the most well-known, they are the pioneer and leader in this regard. But e-commerce transaction model invisible transactions is still in constant development and perfection, there are many areas still blank, and leave much room for development. And extend their value-added services is still in a starting stage, many areas are still waiting for service under development and it is based on the current situation and to propose ideas building special background data supermarket e-commerce platform.

\section{The Status of Data Analysis}

Data analysis in China is still at an initial stage, a lot of data analysis is essentially dependent on the government, completely independent of private enterprises are not many, in addition, there are a lot of consulting firm offers some data analysis. In China, the commercial nature of the data analysis, the company produced in the late 20th century, most of these companies are market-oriented 
investigation. In recent years, the domestic data analysis company has made great progress, as so far there are about 2000 to provide data analysis company, with more than half of the companies are small and medium enterprises engaged in market research, relatively large-scale enterprises and more data analysis for the well-known foreign companies in China offices or joint ventures, they are about more than 20 (Accenture, Standard \& Poor's, etc.), these companies or offices in each major industry well-known foreign companies or joint ventures provide service.

Chinese state-owned, private, and other domestic enterprises now demand is still insufficient data, the less-funded enterprises as a target data analysis difficult for companies to survive. According to the survey, the annual turnover of more than one hundred million RMB ranked 1-2 in front of a few very large data analysis company in the country is only nine. Taken together, the current status of the domestic industry, data analysis can be summarized as: the late start, the scale is too small, lack of experience, no mature development environment, the lack of relatively mature and improve industry standards, national consciousness in the data analysis of the difference, insufficient demand data analysis and technical analysis backward.

Shortage of professionals in the industry, data analysis, data analysis leading to insufficient capacity, the overall low level of these factors led to the analysis of industry data showing the state of labor-intensive, but the analysis of the data should be knowledge-intensive industry, we can see our data analysis urgent need to develop the industry. At present, domestic enterprises to provide data analysis to provide customers with more data to the original data or data only through roughing, roughing data just some shallow analysis of the raw data processing on the basis of such data and technical knowledge content is very low, far less than the foreign level data analysis. Thus, our data analysis, there are many shortcomings, but it is only because of the low level of development it means there is a big space for development, there is a huge market to be tapped.

\section{The Definition of E-Commerce}

E-commerce is a narrow understanding of e-commerce development in the early formation of the Internet has just started to develop at that time and people gradually began to explore the possibilities for trade via the Internet. So narrow understanding of e-commerce refers to the use of the Internet by electronic means, and information technology to business activities.

Broad definition of e-commerce and e-business previously mentioned domestic was widely endorsed by substantially equivalent means of using a set of electronic tools for business activity in the business process. Most of these instruments contain advanced technology content, tools main e-mail and electronic data interchange (exchange data), an electronic bulletin board (obtain data), barcodes (automatic data capture) and the like. Not just a technical means to achieve this level of concern on the face of business, but concerned about their situation, focus on business management, paying attention to various industries under the open environment of the Internet.

\section{Data Analysis}

Data analysis is the concept of architecture (SOA) service-oriented data integration applications generated. SOA service-oriented architecture provides a component model that divides an application into different types of functional units, functional units representing the different services, while the component model between the different types of well-defined functional units Interface and seeks to contract the services connected. Such an interface definition is used internationally accepted neutral standard that is independent of the hardware platform and services 
throughout the operating system can be used to describe any kind of programming language, such services can reach a unified, generic way to interact purpose.

Analysis of data generated in the information society, the main purpose is to disseminate data and information services. It is a product of modern economic activity and service sector plays an important role in the present. Like Web services, data analysis can be defined as having a self-describing data module and loosely self-contained function in a distributed heterogeneous data. A series of criteria such as: XML, XML Schema and other support interoperability between these data modules.

\section{The Characteristic of Data Analysis}

After analysis, data analysis features in the following aspects.

There are those who need the data in a specific period of time to a data and information requirements beyond this time the demand disappears signs are everywhere in real life; generates data are collected in all walks of life in a certain period of time, such as weekly, monthly, annual, etc. these data form over time will continue to have new data generation stage, if beyond the prescribed period will lose the value of the data used.

There are many data requirements are the reason they have data needs because they need to use the data to help them make decisions, so the data analysis needs to have a strong professional, so that it may give the user the correct guidance of real life. Expert and authoritative analysis of the data providers need all walks of life to support the development of their business, only a professional service in order to get the data requirements of identity, only to have a very deep understanding of the industry can only be scientific analysis of data and effective market research and create exact customer needs, with differences of professional data products.

Data analysis process involves data needs by a variety of elements of data analysis provider, data analysis, content, data analysis strategy, and some elements are not required in many cases an important consideration in the data analysis, data analysis, such factors involved less Some, according to the principle of combination, there is a lot of service mode. For example, when there are four elements involved in three modes, when the two elements involved in the presence of six modes

River of digital data and human life is indispensable, since the transaction with the goods, the role of data can imagine, today all social activities are inseparable and digital data. In each of the government departments, enterprises and individuals must work with data, it is already composed an important part of our lives. In between these data include the entire social development and change the law, as well as members of society to each other relevant information. Data is the best portrayal of the true history, which is a complete reproduction of each of the historical process, while based on the data can predict the future development of society, the role of the data shows how important it is, therefore, the data It needs analysis is extremely broad.

Speaking at the second property in the data analysis expertise, professionalism exists, because the analysis of the data needed to provide authenticity can more effectively serve the needs of those data, data analysis and data provider true pseudo also affect its reputation, it is an important determinant of its ability to smooth business stay in business. But how to judge the authenticity of the data is a very difficult problem, this is a huge obstacle to the process of data analysis in the presence of. So far, the world no one agency can assess the authenticity of the data, in which people are living according to their own perception and experience to speculate authenticity of the data, but often get the wrong result of speculation. Only real data to form a support service, but really difficult to get real data, so data analysis is not easily achievable. 


\section{The Data Analysis Operating Strategy of the E-Commerce Platform}

As we all know, network marketing than traditional marketing in commodity prices has a great advantage, because saves a huge amount of internet marketing promotion and distribution costs in the course of business. Based on this, the price of Internet Marketing for both supply and demand is a win-win, and then the product pricing strategy of both supply and demand is also beneficial. Given the above analysis, China's e-commerce platform for data analysis will take the following operating strategies:

When the product pricing, the market price instead of the traditional cost accounting and desired profit margin to determine, but full attention to the client's feelings, not data analysis providers feel that their product worth, but to the customer to judge how much the value of the service to customers on the market should determine the acceptable price for the benchmark. Of course, customers always want the price of services as low as possible, therefore, to provide customers with what they really need and suitable products to customers and make them feel attracted good value for money. In determining the cost side, leading to the market price, the market price is determined after consideration of how companies should maintain the cost level in order to ensure the expected profit, expected even if not high profit margins, companies can also be a huge amount of traffic to make up, data analysis e-commerce market has such potential. In competition with the industry, to take the initiative to take the competition for rivals to take action before competition means always make yourself in the driving position, and will not be controlled by others. Enhance service awareness, to establish good customer relations, fight for customer preference, promotes consumption again. Release of data analysis products, to highlight the specificity of their products, making their own products in a number of areas, industries or technologies have irreplaceable, so you can attract more customers. The establishment of an expert group of high-quality improves the quality of data analysis products, increase customer satisfaction and sense of dependence on the product.

\section{Conclusion}

With the advent of the information age, businesses need for data analysis will be increasing, the user how to find accurate and effective data according to their needs in a large amount of data in the data analysis has important significance. Although some of the results provided by this study was the analysis of the data e-commerce platform, but there are still many issues that need further discussion and improvement, for this study we have not yet encountered problems and possible future direction of development, follow-up study can be further studied.

\section{Reference:}

[1] The usage of the Internet in Germany (in German). Market Research Study. http://www.mentasys.com/files/atfacts_extra_eCommerce_200203.pdf.2002.

[2] T. Saracevic. Relevance: A Review of and a framework for the thinking on the Notion in information science. Journal of the American Society for Information Science, 1975, 26(6): 321-343.

[3] M. Balabanovic, Y. Content-Based, Collaborative Recommendation. Communications of the ACM, 1997,40(3):66-72.

[4] Kalakota Ravi, Andrew B. Whinston. Electronic Commerce: A Manager's Guide. Addison Wesley Longman, lnc.1997. 